\title{
Caminhos investigativos em etnomatemática: perspectivas, experiências e teorizações
}

\author{
Investigative ways in ethnomathematics: \\ perspectives, experiences and theorizations
}

José Roberto Linhares de Mattos ${ }^{1}$

(1) http://orcid.org/0000-0002-4075-6764

José Sávio Bicho²

(1) http://orcid.org/0000-0001-7616-6961

\begin{abstract}
Resumo: Esta entrevista narrativa documenta questões relacionadas aos caminhos investigativos em Etnomatemática a partir do diálogo virtual entre José Roberto Linhares de Mattos e José Sávio Bicho, com base no ponto de vista do primeiro autor. No período de maio a junho de 2019, a entrevista foi realizada por e-mail, com finalidade de atender convite para publicação de entrevista na Ciência e Saber em Foco. A textualização da entrevista destaca um olhar especializado sobre a pesquisa em etnomatemática, focando perspectivas, experiências e teorizações, além de engendrar itinerários e olhares a partir de vivência e trajetória profissional do professor e pesquisador que concedeu a primeira entrevista à revista eletrônica do Curso de Licenciatura em Matemática da Universidade Federal do Amapá.

Palavras-chave: Educação Matemática, Pesquisa em Etnomatemática, Entrevista Narrativa.
\end{abstract}

Abstract: This narrative interview documents questions related to the investigative pathways in ethnomathematics from the virtual dialogue between José Roberto Linhares de Mattos and José Sávio Bicho based on the point of view of the first author. In the period from May to June 2019, the interview was conducted by e-mail, to attend an invitation to publish an interview in Science and Knowledge in Focus. The textualization of the interview highlights a specialized look at the research in ethnomathematics, focusing on perspectives, experiences and theorizations, besides engendering itineraries and looks from the experience, and professional trajectory of professor and researcher who gave the first interview to the electronic journal of the Licentiate Course in Mathematic at the Federal University of Amapá.

Keywords: Mathematics Education, Research in Ethnomathematics, Narrative Interview.

\footnotetext{
${ }^{1}$ Doutor em Ciências (UFRJ), com realização de um Programa de Pós-Doutoramento em Educação no Instituto de Educação da Universidade de Lisboa (IEUL). Professor Permanente do Programa de Pós-Graduação em Educação Agrícola da Universidade Federal Rural do Rio de Janeiro (PPGEA/UFRRJ), professor colaborador do Programa de Doutorado em Educação em Ciências e Matemática da Rede Amazônica de Educação em Ciências e Matemática (PPGECEM/UFMT) e professor da Universidade Federal Fluminense (UFF). E-mail: jrlinhares@gmail.com.

2 Doutor em Educação em Ciências e Matemática (UFMT) e professor da Universidade Federal do Sul e Sudeste do Pará (UNIFESSPA), Instituto de Ciências Humanas ( $\mathrm{ICH})$, lotado no Curso de Licenciatura do Campo. E-mail: saviobicho@yahoo.com.br
} 
Figura 1: Fotografias disponíveis no Currículo Lattes.

Figure: Photographs available in the Lattes Curriculum.

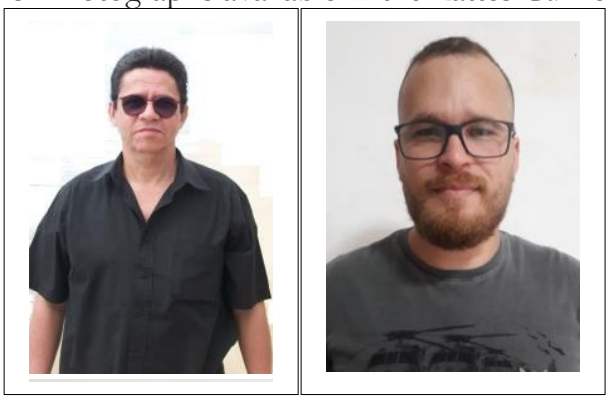

Fonte: WEBSITE DO CNPQ, 2019.

José Sávio Bicho: Professor Linhares, primeiramente gostaria de agradecer sua disponibilidade em participar desta entrevista e dialogarmos acerca de alguns caminhos investigativos em etnomatemática a partir da sua trajetória e ideias. Gostaria de iniciar nosso diálogo pedindo para você nos contar, ainda que brevemente, sobre sua formação, trajetória intelectual e profissional.

José Roberto Linhares de Mattos: Inicialmente, eu quero agradecer a oportunidade de falar um pouco de alguns caminhos de investigação do Programa Etnomatemática por meio do meu entendimento sobre o assunto e das minhas vivências com este Programa de Pesquisa. Eu me formei em bacharel e licenciado em Matemática pela Universidade Federal Fluminense (UFF), tenho o título de mestre em Matemática pela Universidade Federal do Rio de Janeiro (UFRJ) e doutor em Ciências pela mesma universidade. E, também, realizei um Programa de Pós-Doutoramento em Educação pelo Instituto de Educação da Universidade de Lisboa (IEUL), em Portugal, na área de Educação Matemática, na qual trabalhei junto a um Projeto da Fundação para a Ciência e Tecnologia (FCT), chamado Fronteiras Urbanas, coordenado pela investigadora Mônica Mesquita.

Atuo como coordenador do Grupo de Estudos e Pesquisas em Educação e Cultura (GEPEC), certificado pela Universidade Federal Rural do Rio de Janeiro (UFRRJ), na base de dados do Diretório de Grupos de Pesquisas do CNPq e coordenador de um grupo internacional de pesquisa chamado Educação em Fronteiras (EmF), o qual é certificado pela Universidade Federal Fluminense na mesma base de dados do CNPq. O EmF tem como membro inspirador e fundador o professor Ubiratan D'Ambrosio, é composto por pesquisadores do Brasil, Portugal, Espanha e Inglaterra e possui três linhas de investigação, a qual uma delas é Etnomatemática. Eu fui professor do Departamento de Matemática da Universidade Federal Rural do Rio de Janeiro, de 1991 até 2005, quando eu fui para o Instituto de Matemática da Universidade Federal Fluminense.

Em 2004, eu passei a atuar no corpo docente do Programa de Pós-Graduação em Educação Agrícola (PPGEA), que é um programa na área de Educação da CAPES, da Universidade Federal Rural do Rio de Janeiro, no qual permaneço até hoje, e lá eu comecei a trabalhar com pesquisa em Educação Matemática. A partir daí, tenho trabalhado com questões relativas ao Programa Etnomatemática de Ubiratan D’Ambrosio, com aulas em cursos de graduação e pós-graduação, orientações de dissertações de mestrado e pesquisas nesta área. Em 2015, eu ingressei no corpo docente do Programa de Doutorado da Rede Amazônica de Educação em Ciências e Matemática (REAMEC), com polos na Universidade Federal do Mato Grosso, Universidade Federal do Pará e Universidade do Estado do Amazonas, e tenho desenvolvido pesquisas e orientado teses de doutorado em etnomatemática no contexto indígena. Eu tenho me dedicado a pesquisas ligadas ao Programa Etnomatemática, com ênfase em contextos rurais, incluindo produtores rurais, quilombolas, atividades piscatórias, etc., e na educação escolar indígena, tendo escrito e organizado livros, capítulos de livro e artigos na área. 
José Sávio Bicho: Como se deu o seu encontro com as questões relativas à etnomatemática?

José Roberto Linhares de Mattos: Embora tenha realizado um Programa de Pós-Doutoramento em Educação, na área de Educação Matemática, na Universidade de Lisboa, eu venho de uma formação até o doutorado, na área da Matemática, a qual muitos têm uma visão hegemônica e restrita sobre os vários aspectos que dizem respeito ao pensar e inferir matematicamente. Logo após o doutorado, em 2001, eu comecei a me interessar por etnomatemática, lendo livros e artigos de Ubiratan D’Ambrosio.

Ao ingressar no PPGEA, eu comecei a orientar estudantes de mestrado em Educação Matemática e a pesquisar em etnomatemática. Inicialmente, comecei a trabalhar com etnomatemática no contexto rural, investigando a geração e difusão do conhecimento matemático de trabalhadores do campo, e a importância desses conhecimentos para o ensino e a aprendizagem da matemática nas escolas das comunidades e Institutos Federais de Educação.

Posteriormente, passei a atuar também, com o contexto indígena, investigando as práticas docentes de professores indígenas em aldeias de algumas etnias, na relação da educação indígena com a educação escolar indígena, sempre com a preocupação de um retorno dos resultados às comunidades, em especial, à educação escolar.

José Sávio Bicho: Então o seu envolvimento com o Programa Etnomatemática deu-se a partir de experiências acadêmicas e vivências com a educação de camponeses e de povos indígenas. Como foi esse movimento até se tornar educador matemático, trabalhando com elementos socioculturais e conhecimentos matemáticos? De que forma as áreas da matemática acadêmica e da Etnomatemática tem contribuído na reorganização da sua forma de conceber o conhecimento matemático?

José Roberto Linhares de Mattos: O meu doutorado foi obtido com uma tese que abordou sobre regularização de problemas mal postos de equações diferenciais parciais. Cerca de três anos depois de terminar o doutorado, eu comecei a me envolver com a Etnomatemática, com orientação de estudantes de mestrado e apresentando trabalhos em congressos nacionais e internacionais. Porém eu não abandonei a Matemática, tendo ainda publicado alguns artigos sobre equações diferenciais em revistas internacionais, entretanto, o envolvimento com a etnomatemática tornou-se cada vez mais forte.

Apesar de ser professor em um Instituto de Matemática de uma universidade e, portanto, lecionar várias disciplinas da área de Matemática, passei a ter uma visão clara de que o conhecimento matemático acadêmico não é o único que deve fazer parte da formação de um futuro professor da Educação Básica. É claro que um estudante de Licenciatura em Matemática precisa saber bem os conteúdos da Matemática Acadêmica, como cálculo, álgebra e, principalmente, fundamentos de geometria. É condição necessária para uma boa formação universitária. Mas achar que isso é suficiente para que essa pessoa seja um bom professor de matemática no ensino básico é, no mínimo, um descaso com a educação. É preciso que o licenciando estude teorias da educação, metodologias, didática, temas de educação matemática, para que conheça estratégias de ensino e de aprendizagem.

Além disso, é preciso mudarmos a postura dos professores de matemática, para que eles entendam que a matemática acadêmica não é a única que deve ser vista na escola. É preciso contextualizar os conteúdos da matemática escolar, não por meio de estorinhas ou de uma semirrealidade, mas por meio da ancoragem dos conhecimentos por meio de outros pré-existentes na estrutura cognitiva dos estudantes, e que eles trazem à sala de aula. Ou começamos a priorizar essas ações ou estaremos fadados a continuidade do fracasso da educação básica brasileira, no que diz respeito à matemática escolar.

José Sávio Bicho: Com base no seu aprofundamento no estudo e na pesquisa em Etnomatemática nos últimos anos, como você compreende a prática educativa orientada a partir dessa área? 
José Roberto Linhares de Mattos: A Etnomatemática, como um programa de pesquisa, atua não só na investigação da geração e difusão do conhecimento, nos mais variados grupos socioculturais, como, também, e principalmente, auxilia os professores por meio de abordagens metodológicas à sala de aula. É importante que professores de grupos diferenciados e discriminados, como o caso dos indígenas, por exemplo, desenvolvam estratégias pedagógicas, respaldadas no Programa Etnomatemática, para que haja um empoderamento intelectual, político e social desses grupos, que os tornem autônomos e partícipes dos seus processos educacionais.

A educação escolar indígena deve andar de mãos dadas com a educação indígena, com seus processos próprios de ensinagem ${ }^{3}$ e aprendizagem. Tais processos ancoram conceitos da matemática escolar com o desenvolvimento de projetos que envolvem a comunidade, a cultura, as práticas cotidianas, os artefatos e os mentefatos, tendo como referencial teórico-metodológico o Programa Etnomatemática. Dessa forma, as pesquisas em etnomatemática orientam a prática educativa por meio de estratégias que envolvam a cultura do estudante e possibilitem a ensinagem.

José Sávio Bicho: Quais concepções de Etnomatemática se articulam ao teu fazer como professor e pesquisador?

José Roberto Linhares de Mattos: Entendo o conceito de cultura no sentido de Ubiratan D'Ambrosio, como "a associação, simbiótica, de conhecimentos compartilhados e de comportamentos compatibilizados" ". Nessa direção, é necessária uma reflexão sobre todos os aspectos da cultura que apontem para um saber/fazer matemático que independe de conhecimento escolarizado. Esse saber/fazer é parte de uma matemática necessária e suficiente para solucionar problemas cotidianos, muitas vezes complexos, que surgem de necessidades inerentes ao grupo sociocultural em questão e que requerem inferir, avaliar, calcular e estimar, por meio das ticas de matema.

Por meio das suas várias dimensões, o Programa Etnomatemática contribui para as ações pedagógicas realizadas dentro e fora das escolas, em especial, aquelas em comunidades oprimidas e discriminadas. Particularmente, duas dimensões são fundamentais para uma transformação que conduza à liberdade e combata a hegemonia: a dimensão política, pois conduz o indivíduo a refletir sobre sua condição de oprimido e o leva a reconhecer a importância de um pensamento decolonial, isto é, de não apenas reverter a colonização, mas superá-la e transcendê-la por meio de ações de vários tipos; e a dimensão educacional, que propicia a reflexão sobre a necessidade de recuperar a dignidade das pessoas e fortalecer suas raízes.

No caso de povos indígenas, lutar pelo direito à terra, pelos costumes e tradições, por uma educação diferenciada, pela preservação da floresta, é lutar pela cultura; é resistir ao opressor; é libertarse da condição de conivente com o mesmo. É com esse pensamento freiriano que conduzo minha práxis como professor e pesquisador.

José Sávio Bicho: Ultimamente você tem divulgado seu trabalho em livros, comunicações científicas e palestras, onde você traz experiências de pesquisa e de formação de professores e relatos de aulas com povos indígenas e povos do campo. Relate um pouco acerca desta sua atuação e como tem contribuído para educação desses grupos e pesquisa na área.

${ }^{3}$ ANASTASIOU, L. G. C. Ensinar, aprender, apreender e processos de ensinagem. In: ANASTASIOU, L. G. C.; ALVES, L.P. (Org.). Processos de ensinagem na universidade: pressupostos para as estratégias de trabalho em aula. 10.ed. Santa Catarina: UNIVILLE, 2015.

${ }^{4}$ D’AMBROSIO, U. Etnomatemática: Elo entre as tradições e a modernidade. Belo Horizonte: Autêntica, 2011. 
José Roberto Linhares de Mattos: Eu organizei um livro chamado "Etnomatemática: saberes do campo"5 no qual eu trago trabalhos de pesquisadores das regiões Norte, Nordeste e Sudeste que desenvolveram pesquisas junto a produtores rurais e escolas da zona rural, incluindo a educação do campo. Este livro tem prefácio de Ubiratan D'Ambrosio e todos os autores dos capítulos foram meus orientandos de dissertação de mestrado no Programa de Pós-graduação em Educação Agrícola (PPGEA), dos quais alguns já obtiveram o título de doutorado hoje. Com exceção de uma autora, que é professora da rede estadual de educação do Rio de Janeiro, atuando em uma escola agrícola, todos os outros são professores em Institutos Federais de Educação, Ciência e Tecnologia.

Também organizei um outro livro intitulado "Etnomatemática e Práticas Docentes Indígenas", que traz pesquisas com os povos indígenas: Wajãpi do Amapá, Rikbaktsa do Mato Grosso, Guarani e Kaiowá do Mato Grosso do Sul, Mebêngôkre do Pará, povos indígenas do Oiapoque, SateréMawé do Amazonas e os Paiter Suruí de Rondônia e Mato Grosso. Além de três capítulos que tem participação minha como autor, todos os capítulos têm autoria de doutores ou doutorandos que trabalham com educação escolar indígena, dos quais apenas um capítulo, escrito por dois pesquisadores do Mato Grosso do Sul, não é de orientandos ou ex-orientandos meus de mestrado ou doutorado.

Além disso, escrevi, como coautor da pesquisadora Sandra Mattos, o livro "Formação Continuada de Professores de Matemática" ", no qual trazemos pesquisas com professores da Secretaria Estadual de Educação do Rio de Janeiro (SEEDUC), os quais realizaram um curso de formação continuada a distância para professores de matemática, que coordenamos, em uma parceria da SEEDUC com a UFF. O objetivo inicial era a formação em serviço de professores das escolas públicas estaduais com baixo Índice de Desenvolvimento da Educação Básica (Ideb), visando às avaliações de larga escala.

Escrevi, juntamente com uma professora do Instituto Federal do Amapá (IFAP), a qual orientei no mestrado, um livro sobre a "Etnomatemática e a Lei 10.639/03 na Comunidade Quilombola do

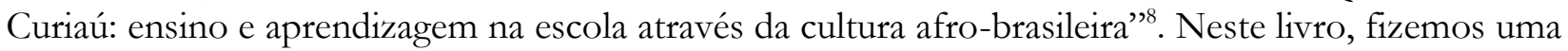
reflexão sobre as percepções de alguns pesquisadores em etnomatemática, referentes a produção e difusão do conhecimento, no que diz respeito à história da educação dos negros, mais especificamente a educação em comunidades quilombolas, e investigamos o ensino e a aprendizagem de matemática na escola da comunidade do Curiaú, em Macapá-AP.

No início deste ano, publiquei um livro chamado "Etnomatemática e Educação Escolar Indígena Paiter Suruí", que contém pesquisas de seis anos nas aldeias da Terra Indígena Sete de Setembro do povo Paiter Suruí. Este livro tem prefácio da antropóloga e pesquisadora Bety Mindlin, que é uma das maiores conhecedoras do povo Paiter, e posfácio da pesquisadora Sandra Mattos. O livro tem coautoria de um professor do Instituto Federal de Rondônia, que foi meu orientando no mestrado e no doutorado, e que trabalhou com a etnomatemática na educação escolar indígena Paiter. Além dos livros, publiquei vários capítulos de livros e artigos em periódicos, que também tratam da etnomatemática e sua atuação em escolas. Eu já orientei mais de 30 estudantes de mestrado no PPGEA/UFRRJ e dois estudantes de doutorado da Rede Amazônica de Educação em Ciências e Matemática (REAMEC/UFMT/UFPA/UEA).

Atualmente, eu oriento outros dois estudantes de doutorado na REAMEC, uma estudante da

${ }^{5}$ MATTOS, J. R. L. (Org.). Etnomatemática: saberes do campo. Curitiba: CRV, 2016.

${ }^{6}$ MATTOS, J. R. L.; MATTOS, S. M. N. (Org.). Etnomatemática e práticas docentes indígenas. Jundiaí: Paco Editorial, 2018.

${ }^{7}$ MATTOS, S. M. N.; MATTOS, J. R. L. Formação continuada de professores de matemática. Curitiba: Appris, 2018.

${ }^{8}$ LIMA, E. D. B.; MATTOS, J. R. L. Etnomatemática e a Lei 10.639/03 na Comunidade Quilombola do Curiaú: ensino e aprendizagem de matemática na escola através da cultura afro-brasileira. Saarbrucken: Novas Edições Acadêmicas, 2017.

${ }^{9}$ MATTOS, J. R. L.; FERREIRA NETO, A. Etnomatemática e educação escolar indígena Paiter Suruí. São Paulo: Ed. Livraria da Física, 2019 
Universidad Nacional de Rosário, na Argentina e um estudante da Universidade do Minho, Portugal, todos trabalhando com etnomatemática. Portanto, isso contribui para a formação de pesquisadores em etnomatemática e, consequentemente, para a produção de novas pesquisas na área. No periódico Ensino Em Re-Vista pode ser encontrado um artigo ${ }^{10}$ que publiquei com a Sandra Mattos, com as contribuições do grupo de pesquisa GEPEC na formação de novos pesquisadores no Brasil.

Da mesma forma, as pesquisas realizadas nas escolas das comunidades contribuem para o ensino e a aprendizagem da matemática escolar por meio de contextualizações, do uso dos saberes dos membros das comunidades e da ancoragem de novos conhecimentos por meio de outros que são trazidos pelos alunos para a sala de aula e que conduz a uma aprendizagem significativa.

Assim, as pesquisas realizadas contribuem para um empoderamento dos membros das comunidades, valorizando e reforçando aspectos culturais. Apenas para citar um exemplo, eu orientei um indígena Paiter no mestrado, chamado Gamalonô Surui, que é diretor da escola indígena da sua aldeia. O Gamalonô trabalhou com a etnomatemática na metodologia de projetos, na atuação da educação indígena na educação escolar indígena da sua etnia. A dissertação teve uma versão toda escrita no idioma Paiter e foi defendida na aldeia, em português e em Paiter. Ele se tornou o primeiro professor indígena no estado de Rondônia a concluir um mestrado acadêmico e sua defesa teve cobertura das três emissoras de TV locais. Hoje o professor Gamalonô participa de cursos de formação de professores indígenas do projeto Açaí, dá palestras e apresenta trabalhos em eventos.

José Sávio Bicho: De que forma a Etnomatemática tem se inserido nos processos de ensino, aprendizagem e formação docente?

José Roberto Linhares de Mattos: O Programa Etnomatemática tem se inserido, de várias formas, tanto nos processos de ensinagem e de aprendizagem na educação escolar, como na formação do professor. As ações desse programa de pesquisa no currículo são de fundamental importância à prática do professor e à aprendizagem dos estudantes.

O Currículo Trivium de Ubiratan D’Ambrosio foi pensado para incorporar os instrumentos comunicativos, que incluem informações escritas e de cálculos na vida cotidiana; os instrumentos analíticos, que incluem modelos e simulações da vida cotidiana; e os instrumentos materiais, que incluem o próprio corpo como um instrumento. Esses instrumentos fazem parte dos conceitos de literacia, materacia e tecnocracia.

Esse tipo de currículo possibilita uma pedagogia crítica, para atingir os conhecimentos necessários à sobrevivência e à luta por uma sociedade menos opressora, mais justa e igualitária. Tudo isso nos faz compreender a importância do Programa Etnomatemática para uma reflexão curricular sobre a necessidade de aproximar os conhecimentos escolarizados trazidos pelos alunos das mais diferentes culturas, valorizando o conhecimento deles e o seu poderoso alcance na compreensão de conceitos matemáticos. Isso certamente produzirá uma aprendizagem significativa, no sentido de David Ausubel $^{11}$, da matemática escolar, pois irá ancorar novos conhecimentos àqueles presentes na estrutura cognitiva dos alunos.

José Sávio Bicho: Como sabemos, a perspectiva teórica desenvolvida por Ubiratan D’Ambrosio sobre o Programa Etnomatemática tem orientado pesquisas em diferentes contextos brasileiros. É um autor reconhecido internacionalmente pelo seu legado nessa área de pesquisa. Além dele, que outros autores oferecem referências para suas reflexões sobre essa área? Quais as convergências das ideias desses

\footnotetext{
${ }^{10}$ MATTOS, J. R. L.; MATTOS, S. M. S. Contribuições do GEPEC/PPGEA/UFRRJ na formação de novos pesquisadores no Brasil. Ensino em Re-Vista, Uberlândia, v. 25, n. 3, p.650-670, Set./Dez./2018

11 AUSUBEL, D. P. Aquisição e retenção de conhecimentos: uma perspectiva cognitiva. Trad. Ligia Teopisto. Lisboa: Paralelo, 2000.
} 
autores com a área?

José Roberto Linhares de Mattos: É verdade que Ubiratan D’Ambrosio é o pesquisador em etnomatemática com maior reconhecimento nacional e internacional, merecidamente, é claro, pois foi quem introduziu o termo e melhor formulou o conceito, e suas ideias têm conduzido minhas pesquisas. Mas é fato que outros pesquisadores brasileiros, como Gelsa Knijnik, Eduardo Sebastiani e Maria do Carmo Domite têm uma importante atuação na área, e são referências para qualquer pesquisador que trabalhe com etnomatemática nos contextos rural, indígena e formação de professores, no Brasil.

Portanto, esses autores não poderiam deixar de fazer parte do meu referencial teórico e de direcionar minhas reflexões nas várias dimensões da etnomatemática. Gelsa Knijnik tem vários trabalhos em etnomatemática no contexto da educação do campo, com um forte envolvimento com as dimensões da etnomatemática, em especial a política e a pedagógica. Currículo, práticas, educação popular em movimento dos sem-terra e questões de resistência, são relacionadas e conectadas por ela com a etnomatemática.

Eduardo Sebastiani Ferreira tem uma grande experiência com trabalhos em aldeias indígenas na década de 1980. Ele foi pioneiro em trabalhos com etnomatemática no contexto indígena no Brasil, atuando diretamente com a educação indígena em algumas etnias do Mato Grosso, e tem publicações envolvendo educação indígena e educação escolar indígena, na dimensão educacional da etnomatemática.

Já Maria do Carmo Domite é, indiscutivelmente, uma grande referência para todos nós na área de formação de professores, em especial, formação de professores indígenas. Ela trabalhou com formação de professores indígenas Guarani, Tupi, Kaingang, Terena e Krenak do Estado de São Paulo, tendo coordenado um Curso de Formação Intercultural Indígena e outro de Magistério Indígena. Seus trabalhos são direcionados à perspectiva da dinâmica cultural do encontro, estando muito ligados à pedagogia de Paulo Freire, em uma aproximação estreita com as ideias desse autor e de Ubiratan D’Ambrosio, relacionadas à dimensão pedagógica da etnomatemática.

Dessa forma, os trabalhos desses autores estão presentes, de alguma forma, nas análises e reflexões que faço nos resultados de minhas pesquisas em etnomatemática no contexto indígena e no contexto rural. Apesar de algumas divergências pontuais que possam haver sobre o modo de pensar de algum autor, as ideias desses três autores convergem para o que queremos na etnomatemática, que é a valorização da cultura por meio da conscientização política e pedagógica na educação escolar.

José Sávio Bicho: Professor, diante da atual conjuntura em que vivemos no nosso país, na qual presenciamos e somos expectadores dos ataques aos direitos adquiridos e de estratégias de apagamento das minorias, acredito que concordamos que fazer pesquisa embasada no Programa Etnomatemática é uma possibilidade para reconhecer no ambiente acadêmico os saberes dos grupos socioculturais, suas lutas e trajetórias. Assim, por último, quais são as questões emergentes para o campo da Etnomatemática e o que você pensa sobre o papel da universidade neste contexto?

José Roberto Linhares de Mattos: Sem dúvida, no atual momento que atravessamos, em que o mundo vive uma ascensão da extrema direita em alguns países, o Programa Etnomatemática tem uma importância crucial na educação para o futuro. No Brasil, o surgimento de grupos apoiadores da retirada de conquistas e de ataques aos direitos humanos e constitucionais está nos levando a uma situação preocupante. Em um governo criado para defender os interesses de grandes grupos econômicos a educação acaba se tornando a vilã, pois ela é capaz de esclarecer os jovens e promover uma libertação da opressão, por meio da práxis.

Não é à toa que Paulo Freire é combatido por essas pessoas que compactuam com grupos de extrema direita, sendo seus ensinamentos taxados de ideologia marxista e querendo torná-lo um grande vilão, para poder eliminar suas ideias das salas de aula, diferentemente do que acontece em países 
desenvolvidos. Dessa forma, é importante que nós, educadores trabalhemos na direção de reverter essas ações, por meio de nossas práticas docentes. Trabalhar com o Programa Etnomatemática permite a nós, pesquisadores, avançar no combate a esses ataques à educação e, em particular, aos oprimidos, sejam eles minorias ou não.

As nossas pesquisas em etnomatemática permitem-nos levar para o ambiente acadêmico a história de grupos socioculturais, suas trajetórias de lutas e resistência, a importância da valorização de suas culturas e as ações que eles desenvolvem no seu ambiente e que beneficiam a todos nós. Por exemplo, no caso dos indígenas, várias ações pedagógicas de sustentabilidade e preservação das florestas, desenvolvidas por etnias indígenas, são levadas às salas de aula das escolas das aldeias, pelos professores indígenas, e ensinadas aos jovens. Essas ações beneficiam a todos nós que precisamos da floresta em pé, e precisam ser compartilhadas no meio educacional não indígena, para que todos saibam a importância dos indígenas e de suas terras para o mundo.

O povo indígena Zoró, no Mato Grosso, tem um projeto de reflorestamento com dois viveiros com 30.000 mudas de árvores nativas da região amazônica. No primeiro semestre de 2019, foram reflorestados 10 hectares com mudas de árvores nativas em áreas devastadas pelos não indígenas. As ações desse projeto são trabalhadas pelos professores indígenas na educação escolar indígena Zoró. Os Paiter Suruí de Rondônia e Mato Grosso, têm um projeto de monitoramento da floresta contra a ação de madeireiros, que permite-os detectar invasões ilegais em suas terras. Eles são grandes produtores de castanha do Pará e estão desenvolvendo agora a produção de café clonal que, segundo especialistas, é de excelente qualidade. Eles também têm uma associação de cultivo de plantas medicinais na própria mata, tudo feito sem devastar a floresta. Da mesma forma, eu poderia citar várias outras ações de povos indígenas do Amazonas, Pará, Roraima, Amapá etc.

Diferentemente de alguns não indígenas que destroem as florestas para acumular riquezas, os povos indígenas sabem da importância de suas ações para o futuro dos seus descendentes e da humanidade. Portanto, é importante que ações pedagógicas dessa natureza sejam respaldadas e ampliadas na educação escolar indígena para fortalecer a decolonialidade, que não é apenas reverter a colonização, mas rejeitar a descolonização da maneira como está implantada, por meio de um processo de luta permanente e desconstrução no imaginário social desses grupos. Por isso eles precisam ser empoderados intelectualmente, o que vem sendo feito já há algum tempo, por algumas universidades, com cursos de formação de professores indígenas, licenciaturas interculturais, e cursos de pós-graduação. Por outro lado, é importante levar às escolas urbanas, a etnomatemática dos mais diversos grupos culturalmente diferenciados, para que se estabeleça a necessidade do respeito e da valorização das culturas, e reafirme que nenhuma cultura é superior à outra.

Eduardo Sebastiani já argumentava isso no início da década de 1990 em seu artigo sobre "a importância do conhecimento etnomatemático indígena na escola dos não-índios" "12. As Universidades têm um papel crucial nesse sentido, na formação inicial dos futuros professores de matemática da educação básica, mas é preciso mudar a cabeça de muitos professores universitários, de alguns Institutos de Matemática, que se dizem "matemáticos" e não aceitam outras matemáticas. É o caso da Universidade a qual pertenço e vivo isso no dia a dia no Instituto de Matemática, no qual muitos professores sequer sabem o que é etnomatemática e seu modo de atuação, mas tentam depreciar o trabalho que é feito por pesquisadores desse programa de pesquisa ou mesmo de outra área da Educação Matemática.

Dentre esses professores, encontramos dois tipos: aqueles que são produtivos na área em que trabalham na matemática acadêmica e acham que aquela é a única que interessa, propagando essa hegemonia entre seus pares e seus alunos; e aqueles que se dizem "matemáticos", que na verdade não produzem artigos há muitos anos, ou mesmo nunca produziram, e querem se colocar como elite da

12 FERREIRA, E. S. A importância do conhecimento etnomatemático indígena na escola dos não-índios. Em Aberto, Brasília, ano 14, n. 62, Abr./Jun. 1994. 
matemática acadêmica perante os alunos, porém não têm esse reconhecimento por parte daqueles que compõem o primeiro grupo. Ambos os grupos propagam seus pensamentos hegemônicos e menosprezam os educadores matemáticos e seus trabalhos de pesquisa. Portanto, precisamos enfrentar e resistir a essas hegemonias, mostrando aos nossos estudantes de licenciatura, que a formação de um futuro professor de matemática não se restringe apenas em conhecer os conteúdos da matemática acadêmica.

José Sávio Bicho: Professor Linhares, em nome do Corpo Editorial da Science and Knowledge in Focus, agradeço pela entrevista. Foi muito interessante dialogarmos e conhecermos os itinerários formativos e de pesquisa que você vem percorrendo. Quem sabe a partir da leitura desta entrevista, inspirar outros pesquisadores. Esperamos que as ideias que você trouxe possa suscitar outros questionamentos e reflexões à pesquisa em educação matemática.

Artigo submetido: 21/06/2019.

Artigo aceito: $24 / 06 / 2019$. 